\title{
Abkürzungsverzeichnis und Zitiererläuterung
}

Zur Bezeichnung der antiken Quellen und der rechtshistorischen Sekundärliteratur (Zeitschriften, Sammelwerke, Lexika und dergl.) werden die in der heutigen Romanistik üblichen Abkürzungen verwendet. Insoweit wird auf das Abkürzungsverzeichnis bei Kaser, Römisches Zivilprozeßrecht (München 1966), verwiesen, von welchem nur in den folgenden Fällen abgewichen wird:

BIDR

DogmJb

ED

Enc.Dir.

NDI

RISG
Bulletino dell'Istituto di diritto romano (Kaser: Bull.). Jherings Jahrbücher für die Dogmatik des heutigen römischen und deutschen Privatrechts (Kaser: JherJb Adolf Berger, Encyclopedic Dictionary of Roman Law, Philadelphia 1953 (Kaser: Berger).

Enciclopedia del diritto (Kaser: ED). Novissimo digesto italiano (Kaser: NNDI).

Rivista italiana per le scienze giuridiche (Kaser: Riv.it.).

Für einige (jedenfalls in Deutschland) heute weniger bekannte Zeitschriften, Entscheidungssammlungen oder Sammelwerke des 19. Jh. werden die folgenden Abkürzungen verwendet:

GU

GU N.F.

HansGZ

OGZ

OTE

Weiske

ZRpflVw
Sammlung von civilrechtlichen Entscheidungen des (österreichischen) k. k. Obersten Gerichtshofes, herausgegeben von Julius Glaser, Josef Unger und Josef $v$. Walther. Wien (seit 1853).

Sammlung von civilrechtlichen Entscheidungen des k. k. Obersten Gerichtshofes, begründet von J. Glaser, J. Unger und J. v. Walther, Neue Folge. Wien (seit 1898).

Hanseatische Gerichtszeitung. Hamburg (seit 1880). Allgemeine Osterreichische Gerichtszeitung. Wien (seit 1850).

Entscheidungen des königlichen (preußischen) Obertribunals. Berlin (seit 1837).

Rechtslexikon für Juristen aller teutschen Staaten, herausgegeben von Julius Weiske. Band 1-15. Leipzig 1839-1861.

Zeitschrift für Rechtspflege und Verwaltung (im Königreich Sachsen), Neue Folge. Leipzig (seit 1841). 
In den Literaturnachweisen der Fußnoten, des Literaturverzeichnisses und des Quellenregisters bedeuten römische Zahlen ohne besonderen Zusatz die Bandzahl eines mehrbändigen Werkes, arabische in unmittelbarem Anschluß an einen Zeitschriften- oder Reihentitel die Bandzahl der Zeitschrift oder Reihe, in Klammern dahinter die Jahreszahl (bei Entscheidungssammlungen das Aktenzeichen), hinter einem Komma oder in unmittelbarem Anschluß an den Namen des Autors die Seitenzahl. Hiervon abweichend bedeutet bei Seufferts Archiv die auf die Bandzahl folgende, durch Komma von ihr getrennte Zahl die laufende Nummer der Entscheidung und erst die in [eckigen] Klammern nachgesetzte die Seitenzahl des Bandes. 
